\title{
College Students' Awareness of Irrational Judgments on Gambling Tasks: A Dual-Process Account
}

\author{
ERIC AMSEL \\ JASON CLOSE \\ ERIC SADLER \\ Weber State University \\ PAUL A. KLACZYNSKI \\ University of Northern Colorado
}

\begin{abstract}
In 2 studies, the authors examined college students' awareness of irrational judgments on gambling tasks. Participants could express a preference between 2 gambles with equivalent ratios (1:10 vs. 10:100) for Study 1 or no preference for Study 2. Participants also rated their certainty that each response option (i.e., 1:10, 10:100, no preference) was rational (analytically based processing) or irrational (experientially based processing of the ratio information). Only a minority of participants in each study was certain that the only analytically based, rational response was no preference. Those participants who were unaware of the analytically based rational response engaged in more formal and informal gambling activities in comparison with others. The authors interpreted the results as evidence of the importance of regulating dual analytical and experiential processes on gambling-related decision making and behavior.
\end{abstract}

Keywords: dual-process theory, metacognitive status, ratio-bias task

ONE OF THE MORE COMPELLING AND PERPLEXING questions about gambling is why competent and intelligent young adults are vulnerable to forms of irrational decision making and behavior that their predilections for games of chance expose. Many college students claim to gamble to earn money

The present research was conducted by Jason Close and Eric Sadler in partial completion of the requirements of a bachelor of science degree in psychology. The research was supervised by Eric Amsel, with the advice of Paul A. Klaczynski. A Weber State University RSPG grant awarded to Eric Amsel supported the research. The authors thank Aubrey Jenkins for her help on the manuscript.

Address correspondence to Eric Amsel, Weber State University, Department of Psychology, Ogden Campus, 1202 University Circle, Ogden, UT 84408, USA; eamsel@weber .edu (e-mail). 
(Neighbors, Lostustter, Cronce, \& Larimer, 2002), despite the obvious futility of such a goal. An assessment of more than 20,000 student athletes indicated that more than $60 \%$ of the men and $40 \%$ of the women have participated in a wide variety of gambling activities (National Collegiate Athletic Association [NCAA], 2004). The participation rate is sizable (more than $30 \%$ for men and $19 \%$ for women) for sports betting, which is an activity that is specifically outlawed by NCAA bylaws, which, if violated, can result in a student athlete's losing NCAA eligibility. More generally, young adults are vulnerable to gambling problems and have a lifetime rate of gambling problems that is reported to be three times higher than the general population (Shaffer \& Hall, 2000). The problem or pathological gambling rate on North American college campuses is estimated to be 5-9\% of men and 1-2\% of women (Stinchfield, Hanson, \& Olson, 2006).

College students' vulnerability to gambling-related irrational decision making and behavior may reflect a specific problem among particular students who reason illogically about probability or possess irrational gambling beliefs or misconceptions. Researchers have distinguished between gamblers and nongamblers or between problem gamblers and social gamblers in terms of their demonstration of such cognitive limitations (Joukhador, Maccallum, \& Blaszczynski, 2003; Joukhador, Blaszczynski, \& Maccallum, 2004; Rogers, 1998; Sharpe \& Tarrier, 1993; Sylvain, Ladouceur, \& Boisvert, 1997; Toneatto, 1999; Toneatto, Blitz-Miller, Calderwood, Dragonetti, \& Tsanos, 1997; Walker, 1992). Although valuable in pointing to the general differences between groups, the research has been based on the questionable assumption that vulnerability to irrational gambling decision making and behavior is limited to those people with such cognitive limitations.

A different approach to understanding irrational decision making and behavior has emerged during the past several years. Falling under the broad rubric of dualprocess theories, the central notion is that two cognitive systems are simultaneously involved in the processing of information (Chaiken \& Trope, 1999; Epstein \& Pacini, 1999; Evans, 2003, 2008; Hogarth, 2005; Kirkpatrick \& Epstein, 1992; Klaczynski, 2004; Stanovich \& West, 2000; Toplak, Liu, Macpherson, Toneatto, \& Stanovich, 2007). One of the dual processes is generally considered to be an experiential one, which is characterized as an automatic, spontaneous, and largely unconscious processing of information holistically, minimally, or emotionally, on the basis of learned experiences or informal heuristics. The experiential process can be thought of as an intuition, premonition, or gut feeling about a situation that is experienced immediately. The other process is an analytic one that involves an effortful, systematic, and largely conscious processing of information thoroughly, systematically, and dispassionately, according to the rules of logic and mathematics. These two processes are seen as parallel and interacting in all manners of cognitive activities, from impression formation to decision making.

The dual-process approach to studying irrationality suggests that rather than being unique to a particular subset of people, the entire population may be 
vulnerable to irrational processing of information under conditions that encourage a predominance of experiential processing over analytic processing. In three experiments, Kirkpatrick and Epstein (1992) tested a dual-processing model in a task measuring college students' choice between two equal gambles. Students were given a choice to play a lottery with a 10:100 chance of winning (10 winning tickets and 90 losing tickets in a large tray from which they had one blindfolded draw) or with a 1:10 chance (1 winning ticket and 9 losing tickets in a small tray). Despite being told that the gambles were equivalent, under some conditions, college students showed a tendency to choose the gamble with more winning targets $(10: 100)$ and offered explanations justifying their choice by the greater number of winners in the 10:100 than the 1:10 gamble. Some participants were so compelled by the difference between the equivalent gambles that they reported being willing to pay to guarantee their choice of a preferred gamble. Kirkpatrick and Epstein noted that the ratio-bias effect-which they called the tendency to prefer one of two equal gambles-was strongest in conditions that minimize the analytic processing of gambling information and weakest in conditions that maximize it, a result that has been well-replicated (Alonso \& Fernandez-Berrocal, 2003; Denes-Raj \& Epstein, 1994; Epstein \& Pacini, 2000-2001; Klaczynski, 2001; Kokis, Macpherson, Toplak, West, \& Stanovich, 2002; Pacini \& Epstein, 1999a, 1999b). It seems that illogical reasoning and irrational beliefs or misconceptions about gambling may not be unique to problem or regular gamblers and absent from nongamblers or social gamblers. Instead, the results point to situations of the predominance of experiential processing over analytic processing among college students.

However, those who gamble regularly or problematically may have particular difficulties in regulating the dual processes involved in gambling-related reasoning and decision making. For example, Denes-Raj and Epstein (1994) demonstrated that self-reported frequency of engaging in informal and formal gambling was predicted by students' preference for gambles with higher absolute frequency of winners but lower likelihood of winning (e.g., 9:100, 8:100 or 7:100 vs. 1:10 gambles). It appears that students who are vulnerable to irrational gambling-related decisions and behavior are those with limited ability to rein in and regulate their experiential processing of ratio information in favor of analytic processing, even in such extreme cases.

The present studies examine college students' metacognitive awareness of the dual experiential and analytic processing of gambling information and whether the lack of such awareness is related to their irrational gambling decision making and behavior. We contend that metacognitive awareness is central to the effective regulation of the dual processes (Amsel et al., 2008; Klaczynski, 2004, 2005), which is necessary to limit students' potential vulnerability to gambling-related problems. For example, some gamblers may have little metacognitive awareness of the dual processing of gambling information. They may consider their spontaneous gut feeling to be an analytic analysis of gambling information and represent themselves as 
having made a rational decision. They may never become aware of the results of an analytic analysis or recognize them as rational responses. We characterize these people as having a poor metacognitive status because they unknowingly make irrational decisions due to a misevaluation of their own cognitive activity.

Gamblers with a poor metacognitive status may be more vulnerable to continued gambling-related irrational decision making and behavior than others who knowingly bypass analytic processing in favor of experiential processing of gambling information. Such gamblers may make irrational decisions by relying on a gut feeling, but do so knowingly; that is, they are metacognitively aware that their gut feeling conflicts with an analytic analysis of the situation. In such cases, individuals would represent themselves as having made an irrational decision in light of also having engaged in and being aware of an analytic analysis of gambling information. The availability of such analytic knowledge may limit continued irrational decision making and behavior. We characterize these people as having a competent metacognitive status because although they may make irrational decisions, they do so while being fully aware of this irrationality.

Last, still others may engage in both an experiential and analytic processing of gambling information but arbitrarily choose between them. In these cases, individuals would evaluate as rational the products of both their experiential and analytic processings of gambling information, which could not be reconciled. We characterize these people as having a conflicted metacognitive status because the decisions they make reflect an arbitrary choice between response options generated from analytic and experiential processes, each of which is represented as rational.

Two studies examined college students' regulation of their dual processing of gambling information. Students completed Kirkpatrick and Epstein's (1992) ratio-bias task, which presents them with a choice between two equal gambles. In addition, on a 4-point scale, students judged how certain they were that each response option was rational, on the basis of an analytic processing of gambling information. From these data, students were categorized into one of the three metacognitive status styles previously described: competent (representing only the analytically based correct response option as rational), conflicted (representing both analytically based correct and experientially based incorrect response options on the task as rational), or poor (misrepresenting an incorrect experientially based response option as the only rational one). Study 1 tested whether most students could be categorized into one of the three metacognitive statuses and assessed factors associated with such a categorization, including students' judgments on the ratio-bias task and their frequency of gambling behavior. We predicted that students would be readily categorized into one of the three statuses, and that their status would be related to their reported gambling behavior. We designed Study 2 to replicate the findings of Study 1 and extend the analysis to a nongambling task. We hypothesized again that most students would be categorized into one of the three metacognitive statuses on each task and that their regulatory status would predict decision making and behavior on both tasks. 


\section{STUDY 1}

The goal of Study 1 was to find initial evidence of the three metacognitive statuses implicated in the regulation of dual experiential and analytic information processing systems on the ratio-bias task. Kirkpatrick and Epstein (1992) suggested that students who commit the ratio-bias by preferring one gamble to a mathematically equivalent one intentionally bypass analytically based processing in favor of experientially based processing of the gambling information. They noted, "Subjects readily made choices that, by their own accounts, they recognized as irrational" (Kirkpatrick \& Epstein, p. 542). This analysis was based simply on choices participants made on the ratio-bias task supported by some anecdotal justifications of those choices. However, such information may be insufficient to allow for strong inferences about how the response options were being represented. It is unclear whether participants are truly aware of the irrationality of their decisions on the ratio-bias task in the sense of expressing a preference between two equivalent gambles despite correctly representing a no preference response as the only analytically based rational response option on the task.

To more carefully assess participants' representations of the task, they completed a ratio-bias judgment (R-BJ) task, which was a modified version of the task that Kirkpatrick and Epstein (1992) used. Participants were given a description of two gambles (1:10 vs. 10:100), noting their mathematical equivalence, and were asked to select one. The forced-choice design between the gambles replicated Kirkpatrick and Epstein's procedure to assess whether there is a bias to favor the gamble with the larger number of winners (10:100). As part of the R-BJ task, participants were also asked whether and how much they would be willing to pay for the privilege of choosing one of the pair of gambles to play. Although the forced-choice design required that participants express a preference, a decision to pay for a preferred gamble between two equivalent ones is irrational, reflecting a deep misconception about the concept of mathematical equivalence.

On a 4-point scale, participants also completed a ratio-bias evaluation (R-BE) task that assessed their certainty that having a preference for the $1: 10$, having a preference for the 10:100, or having no preference for either gamble on the R-BJ task reflected an analytically based rational response. Responses on the R-BE task were used to assess the metacognitive status of participants. A competent metacognitive status was defined as being at least moderately (3) or very (4) sure that having no preference is an analytically based rational response but that being not at all (1) or a little (2) sure that preferring the 1:10 or 10:100 gamble is such a response. A poor metacognitive status was defined as being at least moderately (3) or very (4) sure that having a preference for either the 1:10 or 10:100 gamble is analytically based rational responses but being not at all (1) or a little (2) sure that having no preference is such a response. A conflicted metacognitive status 
was defined as being at least moderately (3) or very (4) sure that both having no preference and having a preference for the 1:10 or 10:100 gamble are analytically based rational responses.

We hypothesized that although dual analytic and experiential processes underlie ratio-bias effects, most participants' metacognitive statuses would not be characterized as competent, thereby challenging the claim that irrational judgments were made knowingly on the ratio-bias task. Moreover, it was also predicted that participants' metacognitive status would be related to their tendency to gamble and vulnerability to gambling problems. A competent metacognition status would seem to require both executive control and metaknowledge (see Amsel et al., 2008; Klaczynski, 2004, 2005, 2009). Competent metacognition regarding the dual processes requires the inhibition of experientially based responses that are automatically generated and metaknowledge regarding the normative and functional properties of experiential and analytical processing to distinguish between the adequacy and rationality of their products. With such skills, a metacognitively competent person would know the characteristics of a rational response on a particular task, no matter what response is made on the task.

Because of the variability in metaknowledge (Byrnes, 2001; Klaczynski, 2004; 2005; Kuhn, 2000, 2001) and inhibitory control (Bull \& Scerif, 2001; Kwon, Lawson, Chung, \& Kim, 2000; Peterson, Pihl, Higgins, Seguin, \& Tremblay, 2003), it is possible that not all of the participants in the present study will demonstrate metacognitive competence. For example, those with a poor metacognitive status may be unable or fail to inhibit automatic responses or to reflect on and distinguish between experientially and analytically based responses. Lacking knowledge of a rational response on the task, those whose metacognitive status is poor would be left to judge their automatic and experientially based responses as rational and analytically based ones. In contrast, those whose metacognitive status is conflicted may have the ability to inhibit experientially based responses although they fail to differentiate them from analytically based ones, with each judged as rational and analytically based. We predicted that a higher tendency to gamble and greater vulnerability to gambling problems would be associated with a poor metacognitive status rather than a conflicted or competent metacognitive status.

\section{Method}

\section{Participants}

Participants were 197 (116 women, 81 men) students enrolled in an introductory psychology class at a regional university in Utah. Their professor offered extra credit for their participation. The mean age of the participants was 20.77 years $(S D=4.85$ years; range $=16-48$ years $)$. Most of the participants were 
freshmen $(68 \%)$ or sophomores $(23 \%)$, whereas only a few were juniors $(6 \%)$ or seniors (2\%). Students' self-reported estimated ACT score $(M=22.70, S D=$ 3.88) and estimated high school GPA $(M=3.46, S D=0.47)$ were, as expected, strongly, positively, and directly correlated $(r=.44, N=160, p<.001)$ when age and student status were removed. We randomly assigned participants to one of four groups of approximately 50 participants each, and that assignment was necessary for counterbalancing task order (R-BJ and R-BE task) and order of mention of the two lottery options (1:10 and 10:100 options).

\section{Procedure}

The questionnaire that each student completed included three sections: demographics, R-BJ task, and R-BE task. The demographics questions requested information about participants' age, sex, student status, major, estimated high school GPA, and estimated ACT scores. Participants were also asked about their frequency of formal (e.g., buying lottery tickets, playing slot machines, betting on horse races) and informal (playing cards for money, shooting dice, betting on sports teams) gambling activities in the past 6 months. We obtained these questions verbatim from Denes-Raj and Epstein's (1994) study. However, formal gambling activities are unavailable in Utah, which prohibits the sale of lottery tickets and has neither private nor state-owned casinos. Gambling is an activity discouraged by the religion practiced by the majority of the sample. Despite this, $20 \%$ of the sample reported engaging in formal gambling activites, and $38 \%$ reported engaging in informal gambling activities. However, because of the relatively small number of formal and informal gamblers, we coded the gambling data nominally as present or absent.

We based the R-BJ and R-BE tasks on Kirkpatrick and Epstein's (1992) study and introduced the tasks through the following hypothetical scenario:

For you to win $\$ 100$, select a black ball from a tray holding both black and white balls. You are presented with two trays of balls. The large tray contains 10 black balls and 90 white ones and you have 1 chance to select the black ball while blindfolded. The small tray contains 1 black ball and 9 white ones and you have 1 chance to select the black ball while blindfolded. If your draw a black ball, the money is yours, otherwise you win nothing and the game is over. The odds of selecting a black ball from the large tray are 10:100, which is the same as the odds of selecting a black ball from the small tray (1:10). Even though the odds are identical for the two trays, some people may have a preference as to which one of those trays they would rather choose from.

We presented $6 \times 6$-mm digital pictures of a small tray and a large tray (commercial 4-in. and 8-in. aluminum pie pans) containing the designated number of black and white balls on the left and right sides of the questionnaire, directly below the description of the task. The pictures were taken from the same position above each tray and were matted on black backgrounds. The first-mentioned 
tray in the description was placed on the left side of the page, and the secondmentioned tray was positioned on the right side of the page. The pictures were labeled to specify their contents and rules for selecting a ball. The presence of such visuals has been reported to more strongly elicit the ratio bias among college students (Rudski \& Volksdorf, 2002).

Following Kirkpatrick and Epstein's (1992) research, the R-BJ task requested that participants make a forced choice between the large and small trays. Specifically, they were asked, "If you were given a choice, which tray would you choose from?" Participants could circle the large or small tray, with the first presented response option being the first-mentioned tray in the task description. After they made a choice, participants were asked to explain their response and assess their willingness to pay for the privilege of choosing the tray they would draw from, rather than having a tray picked for them.

We presented the R-BE task as a request for participants'

thoughts about the possible responses on the gambling task. Some responses on the task may be rational ones and based on a formal and deliberate analysis of the logic of the situation. Other choices may not be rational and based instead on an intuitive and automatic, perhaps even an emotional reaction to the situation.

Participants then rated how sure they were that it is rational (a) to have a preference for and choose the large tray, (b) to have a preference for and choose the small tray, and (c) to have no preference for either tray and arbitrarily choose between them. The first-mentioned tray in the task description was also listed first on the R-BE task. Participants recorded their rational certainty judgments for each response option on a 4-point Likert-type scale ranging from 1 (not at all sure) to 4 (very sure).

We administered the questionnaire to all students who had enrolled in introductory psychology courses and who completed an informed consent form. We counterbalanced the order of the R-BJ and R-BE tasks across participants. In addition, we counterbalanced whether the large or small tray was the first-mentioned tray in the general description of the task and first-listed response option on the R-BJ and R-BE tasks. The questionnaires were handed out and completed in class, taking approximately $10 \mathrm{~min}$ to complete.

\section{Results}

Three sets of analyses tested the hypothesis that dual processing systems underlie participants' R-BJs but that most would not be metacognitively competent. We conducted a first set of analyses to test the claim that the ratio-bias is the result of the dual processing of gambling information. As Kirkpatrick and Epstein (1992) predicted, more participants preferred the large $(n=104)$ tray response option than the small $(n=90)$ tray response option, but the difference was not significant (binomial $p=.18$, one-tailed). However, of the 37 (19\%) participants who were willing to pay for their choice of trays, $25(68 \%)$ were 
willing to pay for the large tray, and only $12(32 \%)$ were willing to pay for the small tray (binomial $p<.05$, one-tailed). The tendency for the large tray to elicit more irrational judgments in the form of offering payment to secure it is consistent with the claim that the 10:100 gamble is experientially processed as more advantageous than 1:10 because of the greater number of winning targets.

To further examine evidence of dual processing systems underlying participants' judgments, we analyzed certainty ratings regarding the rationality of each of the three response options on the R-BE task (large tray, small tray, no preference) as a function of their choice of the large or small tray on the R-BJ task. We conducted a 3 (response options) $\times 2$ (response choice) $\times 2$ (task order) $\times 2$ (tray order) mixed-model analysis of variance (ANOVA) on certainty judgments, with response options serving as a repeated measure. The analysis revealed a main response option effect, $F(2,366)=23.75, p<.001, \eta^{2}=.12$ (Greenhouse-Geisser corrected). Participants were more certain that having no preference is rational $(M=2.77, S D=1.02)$ compared with having a preference for the large $(M=2.25$, $S D=0.98)$ or small $(M=2.17, S D=0.88)$ tray, and the certainty for preferring a tray did not differ from each other. However, the Response Option $\times$ Response Choice interaction effect was also significant, $F(2,366)=13.72, p<.001, \eta^{2}=$ .07 (Greenhouse-Geisser corrected). As depicted in Figure 1, participants were more certain of the rationality of their own choice on the R-BJ task than the other choice, but were also as or more certain of the rationality of having no preference than they were of the preferred ratio. The greater certainty of participants of the rationality of their own response option over the other response option was not a result of post hoc endowing as rational a first or a just-selected choice, because the results showed no task-order or tray-order main or interaction effects. This finding suggests that, overall, participants engaged in both an analytic processing of the equal gambles (resulting in their overall certainty that no preference is a rational response) and an experiential processing resulting in their greater certainty that their preferred gamble was a more rational option.

A second set of analyses directly tested Kirkpatrick and Epstein's (1992) claim that participants knowingly make irrational responses on the R-BJ task. To test this claim, participants were categorized as metacognitively competent, conflicted, or poor. Of a total of 193 participants who completed all the R-BE questions, 59 responses ( 29 men, 30 women) were consistent with a competent metacognitive status, defined as being moderately (3) or very (4) certain that no preference is a rational response and not at all (1) or somewhat (2) certain of the rationality of having a preference for the large or small tray. Another 59 (22 men, 37 women) were categorized as conflicted, defined as being moderately (3) or very (4) certain of the rationality of both the no preference response option and the large- or small- (or both) tray response options. Last, 53 participants ( 25 men, 28 women) were categorized as poor, defined as being moderately (3) or very (4) certain of only the rationality of one's own preference for the large or small tray, with judgments for all other response options being 2 or lower. 
Large tray chosen (10:100)

Small tray chosen $(1: 10)$

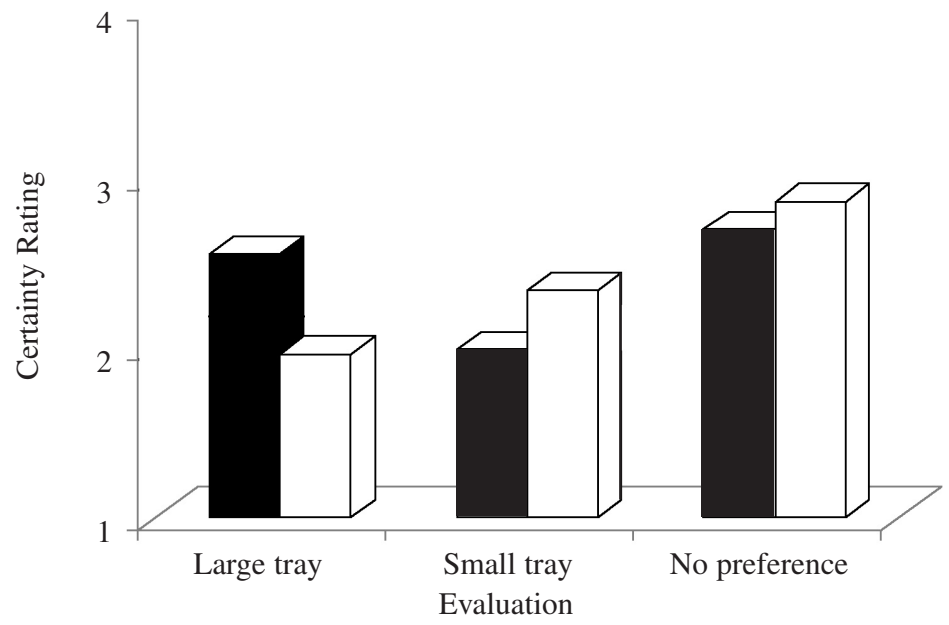

FIGURE 1. Mean certainty ratings for each response option on the ratiobias evaluation task as a function of response option chosen on the ratio-bias judgment task (Study 1).

By de facto transforming the 4-point rating scale into a 2-point scale ranging from 1-2 (rationally uncertain) to $3-4$ (rationally certain), there were $8\left(2^{3}\right)$ possible response patterns, of which 6 were patterns explicitly defined as either competent $(n=1)$, conflicted $(n=3)$, or poor $(n=2)$. As a result, by chance alone, $75 \%$ of sample should have been categorized. In actuality, $89 \%$ of the sample was categorized, which was significantly above chance (binomial $p<$ .001), suggesting that the categorization system is not simply tapping random variation on the R-BE task.

Participants who were categorized in different regulatory groups were no different in age, sex, student status, and estimated GPA. However, they were different in estimated ACT scores, $F(2,143)=14.08, p<.001, \eta^{2}=.16$. Those who were metacognitively competent reported having higher estimated ACT scores $(M=24.60, S D=4.00)$ than those who were conflicted $(M=21.50, S D$ $=3.62)$ or poor $(M=21.20, S D=3.13)$, and they were no different from each other. The finding confirms other research (Amsel et al., 2008) and is consistent with claims of a connection between general intelligence, academic skills, and reasoning ability (cf. Perkins \& Grotzer, 1997).

A third set of analyses explored the gambling-related decisions and behaviors of participants from each metacognitive status (see Table 1). We conducted a one-way ANOVA by metacognitive status on whether participants 
TABLE 1. Gambling-Related Decisions and Behaviors, By Regulatory Status (Study 1)

\begin{tabular}{lccc}
\hline \hline & \multicolumn{3}{c}{ Regulatory status (\%) } \\
\cline { 2 - 4 } & $\begin{array}{c}\text { Poor } \\
\text { Gambling-related decision or behavior }\end{array}$ & $\begin{array}{c}\text { Conflicted } \\
(n=59)\end{array}$ & $\begin{array}{c}\text { Competent } \\
(n=59)\end{array}$ \\
\hline $\begin{array}{l}\text { Pay for tray } \\
\text { Engage in gambling }\end{array}$ & 36 & 17 & 8 \\
$\quad$ Formal & 26 & 25 & 12 \\
$\quad$ Informal & 59 & 36 & 28 \\
$\begin{array}{l}\text { Ratio bias } \\
\text { Large tray } \\
\text { Small tray }\end{array}$ & 62 & 48 & 54 \\
\hline
\end{tabular}

Note. Regarding composite gambling score, poor $=.85$, conflicted $=.61$, and competent $=.41$.

were willing to pay for their preferred gamble. Running an ANOVA on dichotomous data to assess differences in proportions or percentages is justified when degrees of freedom are sufficiently large (see D'Agostino, 1971, 1972; Lunney, 1970). The percentages of participants by metacognitive status who were willing to pay for a preferred tray were significantly different, $F(2,169)$ $=7.27, p<.01, \eta^{2}=.08$. Follow-up Fisher LSD (least significant difference) post hoc tests showed that compared with other participants, more of those categorized as having a poor metacognitive status paid to secure a preferred tray. The percentages of participants by metacognitive group who reported engaging in informal gambling over the past 6 months were also significantly different, $F(2,169)=5.81, p<.05, \eta^{2}=.07$. Again, follow-up LSD post hoc tests showed that, compared with those in other statuses, more of those categorized as having a poor metacognitive status engaged in informal gambling activities. Poor and conflicted participants engaged in more formal gambling than those who were competent; however, the statistical test of this difference only approached significance, $F(2,169)=2.32, p=.10, \eta^{2}=.03$. A composite gambling score (from 0 to 2) was computed for each participant on the basis of whether any formal (scored as 1) or informal (scored as 1) gambling activity had been reported. The mean composite gambling score was higher for those categorized as poor rather than for those categorized as competent with each of the latter scores being no different from the score of those categorized as conflicted, $F(2$, $168)=5.52, p<.05, \eta^{2}=.06$, with LSD follow-up tests. Last, only the choices of metacognitively poor participants demonstrated the predicted ratio-bias effect on the R-BJ task. Metacognitively poor participants selected the large tray more often than the small one, despite the two offering equal chances of winning (binomial $p<.05$, one-tailed). 
Partial correlations were computed between the composite gambling scores and each metacognitive status, independently of the demographic variables of age, sex, status, estimated high school GPA, and estimated ACT scores. The composite gambling score correlated negatively with a competent metacognitive status $(r=-.30, n=154, p<.001)$ and positively with a poor metacognitive status $(r=.20, n=154, p<.05)$. These findings point to the value of metacognitive status in predicting reported gambling behavior.

\section{Discussion}

The central goal of Study 1 was to find initial evidence of the three metacognitive statuses related to the regulation of dual experiential and analytic processing systems on the ratio-bias task. Although the participants did not demonstrate a significant ratio-bias effect by preferring the large (10:100) tray to the small (1:10) tray in a forced-choice selection, there was other evidence of the operation of dual processes underlying their judgments. This evidence included a tendency for more participants' offering payment to secure the large $(10: 100)$ tray than the small (1:10) tray, and participants rating their preferred tray as more rational than the other one, despite being certain of the rationality of having no preference. The failure to find the ratio-bias effect is not unprecedented in the literature for the condition of participants' making such judgments regarding their own preferences (Alonso \& Fernandez-Berrocal, 2003; Denes-Raj \& Epstein, 1994; Epstein \& Pacini, 2000-2001; Klaczynski, 2001; Kokis et. al, 2002; Pacini \& Epstein, 1999a, 1999b).

These findings also challenge Kirkpatrick and Epstein's (1992) claim that college students knowingly bypass analytic processing of gambling information in favor of experiential processing. Such a response reflects metacognitive competence because it involves appropriately representing analytically and experientially based judgments. Instead, most participants were categorized into less adequate metacognitive statuses in which they showed some misrepresentation of the products of analytically and experientially based processing of the gambling information. Metacognitively conflicted participants represented the products of analytic and experiential processing systems as rational, whereas metacognitively poor participants misrepresented experientially based judgments as the only rational choice. As hypothesized, those participants who were categorized into the latter group engaged in more informal gambling and made more irrational (offering payment for equal gambles) and biased (subject to the ratio-bias effect) decisions than those who were categorized into the other groups. Moreover, because they represent their own biased and irrational judgments as "rational based on formal and deliberate analysis of the logic of the situation," those who are metacognitively poor have no other analytically based interpretations of the gambling information, like those who are metacognitively conflicted or competent. 
One central limitation of the present study was that participants were required to make forced-choice R-BJs. Because participants were forced to make a choice between the large and small trays, it is unclear the extent to which any student knowingly bypasses analytic processes in favor of experiential ones. That is, would participants forego a no preference response in favor of choosing the large or small tray on the ratio-bias task, despite representing that choice as irrational? We directly address this issue in Study 2.

\section{STUDY 2}

We designed Study 2 to assess performance on the ratio-bias task with the addition of a no-preference response option on gambling (lottery) and nongambling task contents. Many researchers have found that only a minority of college students selected the no preference options on the ratio-bias lottery task in the standard condition in which participants make judgments about themselves (Alonso \& Fernandez-Berrocal, 2003; Epstein \& Pacini, 2000-2001; Klaczynski, 2001; Pacini \& Epstein 1999a). However Epstein and Pacini failed to find the ratio-bias effect when the no preference option is made available and students made choices about themselves in the standard condition. Students expressed preference for the 10:100 ratio over the 1:10 ratio in the standard condition only when asked to judge how others would reason on the task (a condition designed to promote experiential processing of the information). Klaczynski (2001) gave adolescents and young adults the ratio-bias lottery task with a no-preference response option. He found an age-related increase in participants selecting the no-preference option, but with only a minority selecting the option even under conditions designed to promote analytic processing (however, see Epstein \& Pacini). To promote analytic reasoning, Klaczynski requested participants to consider what a perfectly logical person would select on the ratio-bias task rather than what they themselves would select. In Alonso and Fernandez-Berrocal's study, high school students were given a nongambling ratio-bias task with an option for no preference in all three perspectives - self, other, and a perfectly logical person. The nongambling ratio-bias task involved participants' being told of a protagonist (self, other, or a perfectly logical person) who applied for one of two jobs that were equal in all characteristics except that Job A had 1 position available for a maximum of 10 applicants and Job B had 10 jobs available for a maximum of 100 applicants. Alonso and Fernandez-Berrocal found a high degree of variability in choice of the option of no preference, from a low of $2.5 \%$ in the other condition (designed to promote experiential processing) to a high of $38 \%$ in the logical condition (designed to promote analytic processing). Alonso and Fernandez-Berrocal also found that only in the other condition did more participants choose the 10:100 ratio option over the 1:10 ratio option, replicating Epstein and Pacini's results.

Together, those studies seem to suggest that the ratio-bias effect could be elicited in certain conditions, even with adding a no-preference option and 
using nongambling task content. However, the results of Alonso and Fernandez-Berrocal's (2003) employment task is difficult to directly compare with other studies because Alonso and Fernandez-Berrocal's study used high school students, who likely have little, if any, experience with the task domain of employment. Also, the narrative of the ratio-bias employment task was longer and more complicated than the narrative for the ratio-bias lottery task. To allow for direct comparison between performance on the ratio-bias task in a gambling and nongambling context, we designed Study 2 for participants to receive parallel ratio-bias lottery and employment tasks. Participants received the lottery or employment task with each task including the no preference response option. We predicted that R-BJ performance on each task would be parallel and reveal evidence of dual processing of ratio information. We also predicted that participants would be reliably categorized into one of the three metacognitive statuses and that the proportion of participants in those statuses would be stable across tasks.

\section{Method}

\section{Participants}

Participants were 199 undergraduate students (106 women, 93 men) who were enrolled in an introductory psychology course and had signed informed consent forms. Their professor offered extra credit for participation. The participants were from the same university as those in Study 1, and they had similar demographic characteristics. The average age of the participants was 21.2 years $(S D=3.85$ years, range $=17-41$ years $)$, and the majority were freshmen $(68 \%)$ or sophomores $(18 \%)$, whereas only a few were juniors $(9 \%)$ or seniors $(3 \%)$. Participants' self-reported estimated ACT score $(M=22.80, S D=3.72)$ and estimated high school GPA $(M=3.37, S D=0.67)$ were similar to those in Study 1 but unexpectedly weakly correlated, $r=.15, n=133, p=.089$, after we removed age and student status. It is unclear why the correlation was so low, but because of the unexpected weakness, the ACT scores and GPA should be interpreted cautiously. Students were randomly assigned to one of four groups comprising approximately 50 students each, and that assignment was necessary for counterbalancing the order of the R-BJ and evaluation tasks over participants and randomly assigning participants to one of the two ratio-bias task contents (i.e., lottery, employment).

\section{Procedure}

As in Study 1, the questionnaire distributed to participants had three sections: demographics and the R-BJ and R-BE tasks. The demographics section requested information such as participants' age, gender, major, academic year, 
estimated high school GPA, and estimated ACT score. We did not request formal and informal gambling information, although we asked participants' their willingness to pay to secure a preferred gamble, which correlated with the composite gambling score, $r=.24, p<.01$, independently of demographic variables in Study 1.

The hypothetical lottery task was similar to the version used in Study 1, slightly altered to be clearer and more in line with the employment task. Participants were introduced to the gambling task with the following narrative:

You enter a lottery in which you can win $\$ 100$. There are two similar jars to choose from and you can draw one ticket (without peeking) from one or the other jar. In Jar A there are 10 tickets, only 1 of which is the winning ticket. In Jar B, there are 100 tickets, only 10 of which are winning tickets. The odds of selecting a winning ticket from Jar A are 1:10 (10\%), which is the same as the odds of selecting a winning ticket from Jar B (10:100 or 10\%). Even though the odds of selecting a winning ticket are the same for the two jars, some people may have a preference as to which jar they would rather choose from.

No pictures accompanied the lottery task in Study 2 as in Study 1, to make the lottery and employment tasks as equivalent as possible. The employment task was modified from Alonso and Fernandez-Berrocal's (2003) study by making the narrative similar to the lottery task, resulting in the following:

You are invited to apply for a job at a company. There are two similar jobs to choose from and you are equally qualified for each job, but can only apply for one. For Job A there are 10 applicants (one of them would be you), only 1 of whom will be selected. For Job B, there are 100 applicants (one of them would be you), only 10 of whom will be selected. The odds of being selected for Job A are 1:10 (10\%), which is the same as the odds of being selected for Job B (10:100, 10\%). Even though the odds are the same for the two jobs, some people may have a preference as to which one of the two jobs they would rather apply for.

The R-BJ task requested that participants make a choice about the lottery or job selected on the basis of their understanding of the best chance of winning a gamble or attaining a job. Participants were offered three choices: Jar or Job A (with 1:10 odds), Jar or Job B (with 10:100 odds), and a no-preference option, which was the only rational choice. Participants were then asked why they made their choice, whether they would be willing to pay for their choice, and how much they would pay.

The R-BE section of the questionnaire was parallel to the version used in Study 1 except for slight wording changes to allow similar wording for the lottery and employment task. Participants were told the following:

Some answers on the task may be rational and based on a logical and thoughtful analysis of the situation. Other answers may not be rational and based instead on an automatic reaction to or gut feeling about the situation. For each of the following, judge how sure you are that it is rational. 
Participants then rated how sure they were that it is rational (a) to have a preference for and choose Jar (Job) A, which had a 1:10 chance of winning (being successful), (b) to have a preference for and choose Jar (Job) B, which had a 10:100 chance of winning (being successful), and (c) to have no preference for either jar (job) and not care which jar (job) is chosen. Participants recorded their rational certainty judgments for each response option on a slightly altered 4-point Likert-type scale ranging from 1 (not at all sure) to 4 (very sure).

Participants received the job or jar version of the ratio-bias task, with the order of R-BJ and R-BE task counterbalanced over participants. We handed out the questionnaires, which took the participants approximately $10 \mathrm{~min}$ to complete in class.

\section{Results}

The data were subjected to two sets of analyses to test the hypothesis that $\mathrm{R}-\mathrm{BJ}$ and regulation performance on each task would be parallel and reveal evidence of dual processing of ratio information. Table 2 reveals that R-BJ performances on the lottery and employment tasks were significantly different from each other, $\chi^{2}(2, N=199)=11.61, p<.01$. Follow-up ANOVAs by task on the percentage of participants giving each response (for a use of ANOVAs with categorical data, see D'Agostino, 1971, 1972; Lunney, 1970) revealed a task effect on 1:10 (Job [Jar] A) responses, $F(1,197)=11.85, p<.001$, and 10:100 (Job [Jar] B) responses, $F(1,197)=4.59, p<.05$.

Regarding the lottery task, the $39 \%$ of participants who chose the nopreference option rivals the percentages that Epstein and Pacini (2000-2001), Klaczynski (2001), and Pacini and Epstein (1999a) found in a similar condition. More participants selected Jar B (10:100) than Jar A (1:10) on the lottery task (ignoring those who selected no preference), but the difference was not significant (binomial $p=.13$, one-tailed). This too parallels others' findings in a similar condition (Epstein and Pacini, 2000-2001; Klaczynski, 2001; Pacini \& Epstein, 1999a).

Regarding the employment task, participants selected Job A (1:10) more often than Job B (10:100; binomial $p<.01$, two-tailed). Rather than ignoring

TABLE 2. Distribution of Judgments on the Job and Jar Tasks (Study 2)

\begin{tabular}{lccc}
\hline \hline & \multicolumn{3}{c}{ Ratio-bias judgment } \\
\cline { 2 - 4 } Task & $1: 10$ & $10: 100$ & No preference \\
\hline Jar (lottery) & 26 & 35 & 39 \\
Job (employment) & 49 & 22 & 29 \\
& & & \\
\hline
\end{tabular}


the denominator in preferring 10 winners to 1 on the lottery task (Klaczynski, 2001), participants in the job task ignored the numerator in preferring 9 competitors to 90 . In their comments explaining their judgments, many participants reported focusing on the number of competitors in the employment task because they believed that fewer competitors for a job would increase their chances of being noticed and hired. That is, participants appeared to think that being seen as uniquely qualified for a job depends more on the absolute number of competitors and less on the ratio of jobs to applicants. This addresses the point that perhaps the ratio-bias job task does not parallel the ratio-bias lottery task in that only the latter task involves a truly randomizing situation.

To further examine evidence of dual processes underlying participants' judgments, we conducted a 3 (response options on the R-BE task) $\times 3$ (response choice on the R-BJ task) $\times 2$ (task content: Job vs. Jar) $\times 2$ (task order: R-BJ first vs. R-BE first) mixed-model ANOVA on certainty judgments, with response options serving as a repeated measure. There was a main response choice effect, with those choosing the no-preference option having an overall higher rational certainty rating (out of 4.00, $M=2.56, S D=0.07)$ than those preferring the $1: 10(M=2.26, S D=0.07)$ or 10:100 $(M=2.26, S D=0.09)$ options, $F(2,187)=5.71, p<.01, \eta^{2}=.05$. As in Study 1, there was a main response option effect, $F(2,374)=27.72, p<.001$, $\eta^{2}=.13$ (Greenhouse-Geisser corrected). Participants were more certain that no preference is a rational response $(M=2.72, S D=0.06)$ compared with a preference for Jar (Job) A $(1: 10 ; M=2.19, S D=0.06)$ or Jar (Job) B $(10: 100 ; M=2.18$, $S D=0.06)$, and the preferences did not differ from each other. Also consistent with Study 1 , there was a significant Response Option $\times$ Response Choice interaction effect, $F(2,374)=45.43, p<.001, \eta^{2}=.33$ (Greenhouse-Geisser corrected). Figure 2 depicts a similar pattern as Figure 1 in that participants who preferred one ratio over the other (1:10 or 10:100) were more certain of the rationality of their preferred ratio than of other options. But they were also more certain of the rationality of the no-preference response option than they were of the nonpreferred ratio. Even those participants who chose the no-preference option were at least "a little" certain of the rationality of having a preferred option. This finding points to the dual experiential processing and analytic processing of ratio information.

There was a Task Order $\times$ Response Option effect, $F(2,374)=3.75, p<.05$, $\eta^{2}=.02$ (Greenhouse-Geisser corrected), which reflected more certain responses regarding the no preference option by participants who evaluated response options first than by those who made judgments first. However, this effect was limited to those who choose the 10:100 response, resulting in a Task Order $\times$ Response Option $\times$ Response Choice interaction effect, $F(2,374)=2.65, p<.05, \eta^{2}=$ .02 (Greenhouse-Geisser corrected). These results suggest that participants with a preference for the 10:100 response better recognize the rationality of the no preference option when first evaluating response options (R-BE task first) than when first making their choice (R-BJ task first). The finding provides additional evidence that task context affects the relative predominance of experientially over 


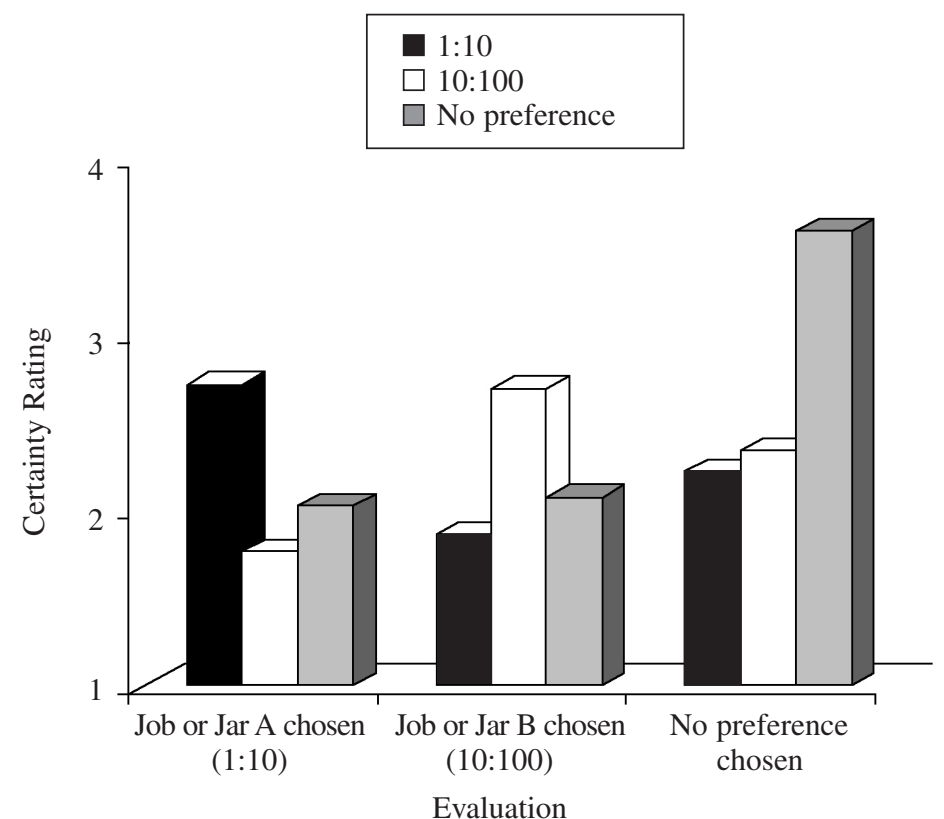

FIGURE 2. Mean certainty ratings for each response option on the ratiobias evaluation task as a function of response option chosen on the ratio-bias judgment task (Study 2).

analytically based processing of ratio information (Alonso \& Fernandez-Berrocal, 2003; Epstein \& Pacini, 2000-2001; Klaczynski, 2001; Pacini \& Epstein, 1999a).

The second set of analyses addressed whether participants could be categorized into a metacognitive status in the same manner as they were in Study 1 and whether category membership would predict judgments. There were 61 (31\%) participants categorized as competent who evaluated themselves as at least somewhat uncertain (score of 1 or 2 ) of the rationality of having a preferred option and at least mostly certain (score of 3 or 4 ) of the rationality of having no preference. More of these participants $(n=39,64 \%)$ made no preference judgments on the RB-J task; and of those who expressed a preference $(n=22), 14$ preferred the 1:10 option, and 8 preferred the 10:100 option. These latter 22 participants were no different from the former 39 participants in any demographic (age, gender, student status, estimated GPA, estimated ACT score) or task-related (condition, task order, or willingness to pay) variable. This small group of metacognitively competent participants whose R-BJ judgment was a preferred option (11\% of the sample) comprises the only ones who can be properly said to have "readily made choices that, by their own accounts, they recognized as irrational" (Kirkpatrick \& Epstein, 1992, p. 542). 
There were $53(27 \%)$ participants who were categorized as metacognitively conflicted, by evaluating themselves as at least mostly certain (score of 3 or 4) about the rationality of having and not having a preferred option. About half of these participants made no preference judgments on the RB-J $(n=26,48 \%)$, and the 27 who had a preference were equally divided between the 1:10 $(n=13)$ and 10:100 $(n=14)$ options. There was a tendency that approached significance for these participants to prefer the 10:100 ratio to the 1:10 ratio on the lottery task ( 9 vs. 4) but to prefer the 1:10 ratio to the $10: 100$ ratio on the employment task ( 9 vs. 5), $\chi^{2}(1, N=27)=3.03, p=.08$.

Last, there were $56(28 \%)$ participants who were categorized as metacognitively poor, by evaluating themselves as at least mostly certain (score of 3 or 4) about the rationality of only having a preferred option. All these participants made judgments on the RB-J task reflecting a preference, with more preferring the 1:10 $(n=35)$ ratio than those preferring the 10:100 $(n=21)$ ratio, a difference that approached significance (binomial $p=.08$, two-tailed). However, their responses differed by task content with more preferring the 10:100 ratio to the $1: 10$ ratio on the lottery task ( 13 vs. 9 ), but preferring the $1: 10$ ratio to the $10: 100$ ratio on the employment task ( 26 vs. 8$), \chi^{2}(1, N=56)=7.21, p<.01$.

We categorized a total of $85 \%$ of the sample, which was significantly above the $75 \%$ expected by chance (binomial $p<.001$ ), again suggesting that the categorization system is not just tapping random variation on the R-BE task but revealing different metacognitive statuses central to regulating dual analytic and experiential processes. Participants who were categorized in different metacognitive statuses were no different in age, sex, student status, estimated GPA, or estimated ACT scores, although the latter two results should be treated with caution because of the weak correlation between them. As in Study 1, dual process metacognitive status was associated with an irrational tendency to pay to secure one of two equivalent lottery or employment opportunities. A 3 (metacognitive status) $\times 2$ (task) ANOVA on the proportion of those participants who would pay showed only a metacognitive status effect, $F(2,163)=3.43, p<.05, \eta^{2}=.04$. More participants whom we categorized as metacognitively poor $(30 \%)$ than those whom we categorized competent $(10 \%)$ were willing to pay for a preferred option, with those who were conflicted (19\%) being no different from the other

TABLE 3. Distribution of Regulatory Statuses, by Task (Study 2)

\begin{tabular}{lllcc}
\hline \hline & \multicolumn{4}{c}{ Regulatory status } \\
\cline { 2 - 5 } Task & Other & Poor & Conflicted & Competent \\
\hline Jar (lottery) & 17 & 22 & 26 & 37 \\
Job (employment) & 12 & 34 & 27 & 24 \\
& & & & \\
\hline
\end{tabular}


two groups. This finding replicates the Study 1 result despite differences in task content and procedure between the studies. Last, the distribution of metacognitive statuses on the two tasks was not statistically different (see Table 3 ), $\chi^{2}$ (3, $N$ $=199)=6.10, n s$. This finding suggests that despite wide differences between the two tasks in eliciting different patterns of responses, each elicited the same proportion of metacognitive statuses.

\section{Discussion}

We designed Study 2 to assess whether R-BJs and dual-process regulation would be affected by adding a no preference response option and nongambling task content. We predicted that judgments and metacognitive status would be stable across tasks and replicate the findings of Study 1 . The data generally supported the hypothesis. The judgments were consistent in many ways with other findings in the literature. Notably, the majority of college students do not fully appreciate the meaning or significance of being told that two ratios are equivalent. Only $40 \%$ of the lottery task participants and $30 \%$ of the employment task participants responded that the mathematical equivalence between the 1:10 and 10:100 ratios means that they should not have a preference between them, although there is some question as to whether the ratio-bias employment task may have equivalent ratios because it is not perceived to be a randomizing situation. This replicated others' findings that a minority of participants had no preference when asked to choose between two equal ratios despite using other tasks and placing participants in other conditions (Alonso \& Fernandez-Berrocal, 2003; Epstein \& Pacini, 2000-2001; Klaczynski, 2001; Pacini \& Epstein, 1999a).

Although we did not find an overall ratio-bias effect in Study 2, there was evidence that the task elicited dual analytic and experiential processes. Among the majority of students who had a preference for one job or jar over another, the students were more certain of the rationality of the no preference option than of the alternative job or jar option. This replicates the finding from Study 1 and supports the notion that participants were processing the information experientially (in preferring one job or jar over another) and analytically (in judging the rationality of having no preference). Such a finding supports the point that the task elicits both processing systems, requiring the regulation of the two systems.

One notable exception to this list of replicated results was the finding that more American college students in this study preferred to apply for a job with a 1:10 chance than of a 10:100 chance of being successful. Spanish high school students preferred the latter to the former (Alonso \& Fernandez-Berrocal, 2003). Alonso and Fernandez-Berrocal argued that the different preferences nonetheless reflect the same experiential processing of the information. However, it is unclear whether the judgmental differences were influenced by age, culture, or task presentation on experiential processing.

Regarding metacognitive statuses, Study 2 replicated the Study 1 findings that most participants could be successfully categorized as competent, conflicted, 
or poor. The roughly equal distribution of metacognitive statuses was shown to be stable across task contents despite the variability in judgments. The styles were unrelated to obvious demographic and background variables. Nonetheless, the styles predicted a variety of judgment biases. Those adopting the poor style, whom we assumed to have limited metaknowledge and inhibitory control skills, were shown to be more vulnerable than others to judgmental biases (i.e., paying for preferred gambles and succumbing to the ratio-bias).

\section{GENERAL DISCUSSION}

The purpose of Studies 1 and 2 was to explore the dual process approach to gambling decision making and behavior. Dual process theory was tested with the ratio-bias task, in which participants are presented with 1:10 and 10:100 ratios in a gambling or employment context. The theory proposes that the ratio information is processed analytically as mathematically equivalent or experientially as involving one ratio having a greater absolute number of winners or losers. A central hypothesis of the research was that college students' vulnerability to irrational decision making and behavior is associated with the manner in which they regulate the dual analytic and experiential processing systems. To identify their regulatory skills, we assessed participants' metacognitive status by measuring their certainty that each ratio-bias response option was an analytically based rational one.

When the two studies of almost 400 college students are combined, about one third of the participants were metacognitively competent. These students were notably less biased than others in processing ratio information although they did not uniformly select the analytically based rational choice on the task. A third of the metacognitively competent participants in Study 2 selected a preferred ratio, suggesting that knowing the analytically based rational response on a task does not guarantee its selection for all participants. Neither task nor demographic variables were associated with metacognitively competent participants' making rational or irrational judgments, leaving open the question of why knowledge of rational judgments does not always translate into responses that are rational. Although some metacognitively competently participants may have followed a hunch, the hunch they followed was represented as an experientially based and irrational one, rather than misrepresented as an analytically based and rational one. The tendency for these participants to follow an appropriately represented hunch appears not to index a gambling problem because few participants reported having engaged in formal or informal gambling activities and fewer participants were willing to pay for a preferred gamble.

Another quarter of the sample who correctly characterized the products of analytic processing as rational but misrepresented the products of experiential processing as rational were coded as metacognitively conflicted. When making a decision, these participants had multiple conflicting rational options from which to choose arbitrarily. Study 2 showed that for half of the time, the participants 
relied on analytic processing and expressed no preference, and for the other half of the time, they relied on experiential processing and expressed a preferred ratio. When they relied on experiential processing, they showed a tendency to be influenced by task content (Study 2). However, being able to identify no preference as an analytically based rational ratio-bias task response appears to limit the vulnerability of these participants to gambling problems. For example, only approximately $20 \%$ of conflicted regulators were willing to pay for their preferred ratios, and a similar minority engaged in gambling activities. This was a much lower rate than that of those categorized as metacognitively poor, who similarly mischaracterized their intuitions as analytically based rational responses.

Metacognitively poor participants were little more than one quarter of the sample and were more biased than others in processing ratio information. They made decisions reflecting a preference for one of two equal ratios (showing the ratio bias) and were more likely to pay to secure their preferred ratio. Because of their exclusive use of intuition, these students were particularly influenced by task context on their judgments (Study 2). Despite making subjective and biased judgments, these participants represented their judgments as rational. These participants appeared to act on their gut feelings about ratios without regard to more formal analyses of them, reflecting perhaps poor inhibitory control and lack of metaknowledge. They may tend to engage in gambling behavior more often because of a misplaced confidence in their experiential processing. A majority of them engaged in formal gambling activities and had a composite gambling score that was twice as high as their peers in the other metacognitive categories.

These findings confirm the claim that how students regulate dual processes, in the sense of being metacognitively aware and in control of analytic and experiential processing of ratio information, predicts their vulnerability to irrational gambling-related decision making and behavior. This vulnerability was associated with metacognitive status independently of various background and demographic variables, suggesting a relatively direct relation between metacognitive status and the measures of vulnerability to irrational gambling judgments and behavior. Future research could further explore whether metacognitive status predicts problem gambling and other risk-taking behaviors. Furthermore, the assumed relation between metacognitive status and skills for inhibitory control and metaknowledge could be pursued. There is much evidence that supports the relation between the inhibitory control, as measured by neuropsychological tasks, and mathematical performance independent of other cognitive and individual difference factors (Bull \& Scerif, 2001; Kwon et al., 2000; Peterson et al., 2003). Kwon et al. in particular found that inhibitory control predicted performance on proportional reasoning tasks, independently of calculation skills, memory capacity, planning ability, and locus of control. The proportional reasoning task involved comparing and relating simple ratios and supported the claim that reasoning about ratios involves skills that inhibit automatic responses to answer in a mathematically sound manner. 
Toplak et al. (2007) found that higher order "mindware problems" (p. 118-119) were an important and autonomous (from cognitive ability and inhibitory skills) predictor of problem gambling. On the basis of a study using a version of the ratio-bias task, Toplak et al. found that a limited availability of procedures implemented by the analytic system, when overriding the experiential processing of information, was associated with problem gambling. Beyond their other limitations, participants with poor metacognitive abilities may be seen as having mindware problems as they lack metaknowledge of the properties of analytically based responses that may motivate them to override experientially based responses.

In conclusion, the capacity to have and act on an intuitive cognitive process (Gigerenzer, 2007; Myers, 2003) is as much a human asset as is the capacity to have and act on an analytic cognitive process (Stanovich \& West, 2000). The purpose of the present research was to demonstrate that these capacities best operate when the two processes are effectively regulated, so that products of each process are accurately represented and either or both processes can be used to direct decision making and behavior, depending on the task and situation (Hogarth, 2005). We found that metacognitive status was an efficient way to measure the extent to which participants effectively regulate their dual processes. We proposed that metacognitive reflection ability and inhibitory control skills are key elements defining competent dual process regulation.

The general finding was that although most college students make less than rational judgments on gambling tasks, those who also demonstrate poor regulatory skills are vulnerable to gambling-related judgment and behavioral problems. A predilection for games of chance or a tendency to make irrational judgments may not indicate vulnerability to gambling problems unless it is known whether the judgments and predilections are the result of poor regulatory skills.

\section{AUTHOR NOTES}

Eric Amsel is a professor and the chair of the Department of Psychology at Weber State University. His research interests are in the development of reasoning from childhood to adolescence. Jason Close received his undergraduate degree in psychology from Weber State University. Currently, he is an academic advisor and respiratory therapist in Ogden, UT. Eric Sadler received his undergraduate degree in psychology and sociology from Weber State University. He is currently working in banking in Ogden, UT, while applying to graduate school. Paul A. Klaczynski is an associate professor in the School of Psychological Sciences at the University of Northern Colorado. His research interests concern developmental changes and individual differences in decision making, social reasoning biases, and stereotype maintenance.

\section{REFERENCES}

Alonso, D., \& Fernandez-Berrocal, P. (2003). Irrational decisions: Attending to numbers rather than ratios. Personality and Individual Differences, 35, 1537-1547.

Amsel, E., Klaczynski, P. A., Johnston, A., Bench, S., Close, J., Sadler, E., et al. (2008). A dual-process account of the development of scientific reasoning: The nature and development of metacognitive intercession skills. Cognitive Development, 23, 452-471.

Bull, R., \& Scerif, G. (2001). Executive functioning as a predictor of children's mathematical 
ability: Inhibition, switching, and working memory. Developmental Neuropsychology, 19, 273-293.

Byrnes, J. P. (2001). Minds, brains, and learning. New York: Guilford Press.

Chaiken, S., \& Trope, Y. (1999). Dual-process theories in social psychology. New York: Guilford Press.

D'Agostino, R. B. (1971). An omnibus test of normality for moderate and large sample size. Biometrika, 58, 341-348.

D'Agostino, R. B. (1972). Relation between the chi-squared and ANOVA tests for testing equality of $k$ independent dichotomous populations. American Statistician, 26, 30-32.

Denes-Raj, V., \& Epstein, S. (1994). Conflict between intuitive and rational processing: When people behave against their better judgment. Journal of Personality and Social Psychology, 66, 819-829.

Epstein, S., \& Pacini, R. (1999). Some basic issues regarding dual-process theories from the perspective of cognitive-experiential self-theory. In S. Chaiken \& Y. Trope (Eds.), Dual-process theories in social psychology (pp. 462-482). New York: Guilford Press.

Epstein, S., \& Pacini, R. (2000-2001). The influence of visualization on intuitive and analytical information processing. Imagination, Cognition, \& Personality, 20, 195-216.

Evans, J. St. B. T. (2003). In two minds: Dual process accounts of reasoning. Trends in Cognitive Sciences, 7, 454-459.

Evans, J. St. B. T. (2008). Dual-processing accounts of reasoning, judgment, and social cognition. Annual Review of Psychology, 59, 387-417.

Gigerenzer, G. (2007). Gut feelings: The intelligence of the unconscious. New York: Viking Press.

Hogarth, R. (2005). Deciding analytically or trusting your intuition? The advantages and disadvantages of analytic and intuitive thought. In S. Haberstroh \& B. Tilman (Eds.), The routines of decision making (pp. 57-82). Mahwah, NJ: Erlbaum.

Joukhador, J., Blaszczynski, A., \& Maccallum, F. (2004). Superstitious beliefs in gambling among problem and non-problem gamblers: Preliminary data. Journal of Gambling Studies, 20, 172-180.

Joukhador, J., Maccallum, F., \& Blaszczynski, A. (2003). Differences in cognitive distortions between problem and social gamblers. Psychological Reports, 92, 1203-1214.

Kirkpatrick, L. A., \& Epstein, S. (1992). Cognitive-experiential self-theory and subjective probability: Further evidence for two conceptual systems. Journal of Personality and Social Psychology, 63, 534-544.

Klaczynski, P. A. (2001). Framing effects on adolescent task representations, analytic and heuristic processing, and decision making: Implications for the normative-descriptive gap. Journal of Applied Developmental Psychology, 22, 289-309.

Klaczynski, P. A. (2004). A dual-process model of adolescent development: Implications for decision making, reasoning, and identity. In R. V. Kail (Ed.), Advances in child development and behavior (Vol. 31, pp. 73-123). San Diego, CA: Academic Press.

Klaczynski, P. A. (2005). Metacognition and cognitive variability: A two-process model of decision making and its development. In J. E. Jacobs \& P. A. Klaczynski (Eds.), The development of decision making in children and adolescents (pp. 39-76). Mahwah, NJ: Erlbaum.

Klaczynski, P. A. (2009). Cognitive and social cognitive development: Dual-process research and theory. In J. B. St. Evans \& K. Frankish (Eds.), In two minds: Psychological and philosophical theories of dual processing (pp. 265-292). Oxford, England: Oxford University Press.

Kokis, J., Macpherson, R., Toplak, M. E., West, R. F., \& Stanovich, K. E. (2002). Heuristic and analytic processing: Age trends and associations with cognitive ability and cognitive styles. Journal of Experimental Child Psychology, 83, 26-52.

Kuhn, D. (2000). Metacognitive development. Current Directions in Psychological Science, 9, 178-181. 
Kuhn, D. (2001). How do people know? Psychological Science, 12, 1-8.

Kwon, Y. J., Lawson, A. E., Chung, W. H., \& Kim, Y. S. (2000). Effect on development of proportional reasoning skill of physical experience and cognitive abilities associated with prefrontal lobe activity. Journal of Research in Science Teaching, 37, 1171-1182.

Lunney, C. H. (1970). Using analysis of variance with a dichotomous dependent variable: An empirical study. Journal of Educational Measurement, 7, 263-269,

Myers, D. (2002). Intuition: Its powers and perils. New Haven, CT: Yale University Press.

National Collegiate Athletic Association (NCAA). (2004). NCAA 2003 national study on collegiate sports wagering and associated health risks. Retrieved May 12, 2004, from http://www.ncaa.org/releases/research/2004/2004051201re.htm

Neighbors, C., Lostustter, T., Cronce, J., \& Larimer, M. (2002). Exploring college student gambling motivation. Journal of Gambling Studies, 18, 361-370.

Pacini, R., \& Epstein, S. (1999a). The interaction of three facets of concrete thinking in a game of chance. Thinking and Reasoning, 5, 303-325.

Pacini, R., \& Epstein, S. (1999b). The relation of rational and experiential information processing styles to personality, basic beliefs, and the ratio-bias phenomenon. Journal and Personality and Social Psychology, 76, 972-987.

Perkins, D. N., \& Grotzer, T. A. (1997). Teaching intelligence. American Psychologist, 52, 1125-1133.

Peterson, J. B., Pihl, R. O., Higgins, D. M., Seguin, J. R., \& Tremblay, R. E. (2003). Neuropsychological performance, IQ, personality, and grades in a longitudinal grade-school male sample. Individual Differences Research, 3, 159-172.

Rogers, P. (1998). The cognitive psychology of lottery gambling: A theoretical review. Journal of Gambling Studies, 14, 111-133.

Rudski, J., \& Volksdork, J. (2002). Pictorial versus textual information and the ratio-bias effect. Perceptual and Motor Skills, 95, 547-554.

Shaffer, H. J., \& Hall, M. N. (2000). Updating and refining meta-analytic prevalence estimates of disordered gambling behavior in the United States and Canada. Boston: Division on Addictions, Harvard Medical School, Harvard University.

Sharpe, L., \& Tarrier, N. (1993). Towards a cognitive behavioural theory of problem gambling. British Journal of Psychiatry, 162, 407-412.

Stanovich, K. E., \& West, R. F. (2000). Individual differences in reasoning: Implications for the rationality debate? Behavioral and Brain Sciences, 23, 645-665.

Stinchfield, R., Hanson, W. E., \& Olson, D. H. (2006). Problem and pathological gambling among college students. In G. S. McClellan, T. W. Hardy, \& J. Caswell (Eds.), Gambling on campus: New directions for student services (No. 113, pp. 63-72). Hoboken, NJ: Wiley.

Sylvain, C., Ladouceur, R., \& Boisvert, J. (1997). Cognitive and behavioral treatment of pathological gambling: A controlled study. Journal of Consulting and Clinical Psychology, 65, 727-732.

Toneatto, T. (1999). Cognitive psychopathology of problem gambling. Substance Use and Misuse, 34, 1593-1604.

Toneatto, T., Blitz-Miller, T., Calderwood, K., Dragonetti, R., \& Tsanos, A. (1997). Cognitive distortion in heavy gambling. Journal of Gambling Studies, 13, 253-266.

Toplak, M., Liu, E., Macpherson, R., Toneatto, T., \& Stanovich, K. E. (2007). The reasoning skills and thinking dispositions of problem gamblers: A dual-process taxonomy. Journal of Behavioral Decision Making, 20, 103-124.

Walker, M. B. (1992). Irrational thinking among slot machine players. Journal of Gambling Studies, 8, 245-261.

\section{Original manuscript received January 13, 2008}

Final version accepted July 18, 2008 
Copyright of Journal of Psychology is the property of Heldref Publications and its content may not be copied or emailed to multiple sites or posted to a listserv without the copyright holder's express written permission. However, users may print, download, or email articles for individual use. 